\title{
Rafting on abiotic substrata: properties of floating items and their influence on community succession
}

\author{
Macarena Bravo ${ }^{1}$, Juan Carlos Astudillo ${ }^{1}$, Domingo Lancellotti ${ }^{1}$, \\ Guillermo Luna-Jorquera ${ }^{1,2}$, Nelson Valdivia ${ }^{2,3}$, Martin Thiel ${ }^{1,2, *}$ \\ ${ }^{1}$ Facultad de Ciencias de Mar, Universidad Católica del Norte, Larrondo 1281, Coquimbo, Chile \\ ${ }^{2}$ Centro de Estudios Avanzados en Zonas Aridas (CEAZA), Coquimbo, Chile \\ ${ }^{3}$ Instituto de Ciencias Marinas y Limnológicas, Facultad de Ciencias, Universidad Austral de Chile, Campus Isla Teja s/n, \\ Valdivia, Chile
}

ABSTRACT: A wide diversity of organisms is dispersed on abiotic floating substrata, but little is known about the succession of fouling communities on these items. The main abiotic floating items found in the oceans (volcanic pumice, plastics, and Styrofoam) differ in 3 principal characteristics, namely surface rugosity, buoyancy, and floating behaviour, confirmed herein by light and electron microscopy (SEM), measurements of buoyancy, and laboratory tests to determine floating stability. In order to examine how these properties affect colonization and community succession on these substrata, 3 experiments were conducted in the field for 14 wk: (1) substrata were permanently submerged to determine if colonization depends on substratum surface ('Rings' experiment); (2) substrata were tethered at the sea surface to examine the importance of buoyancy ('Lines' experiment); and (3) substrata were caged to test the role of their floating behaviour ('Cages' experiment). The most common colonizers in all 3 experiments were diatoms, Ulvales, and clonal ascidians from the genus Diplosoma. Surface rugosity of the substrata had only minor effects on the taxonomic richness of the developing communities. Buoyancy caused some differences in taxon cover, but taxon richness was similar on all 3 substrata. Finally, the floating behaviour at the sea surface had a strong influence on the communities developing on the floating substrata. Plastics (fewest changes in position) presented a higher richness and cover of taxa, while Styrofoam (most positional changes) harboured very few taxa. We conclude that colonization and succession on floating substrata is strongly influenced by positional changes, while surface rugosity and buoyancy appear important only during initial stages of community succession.
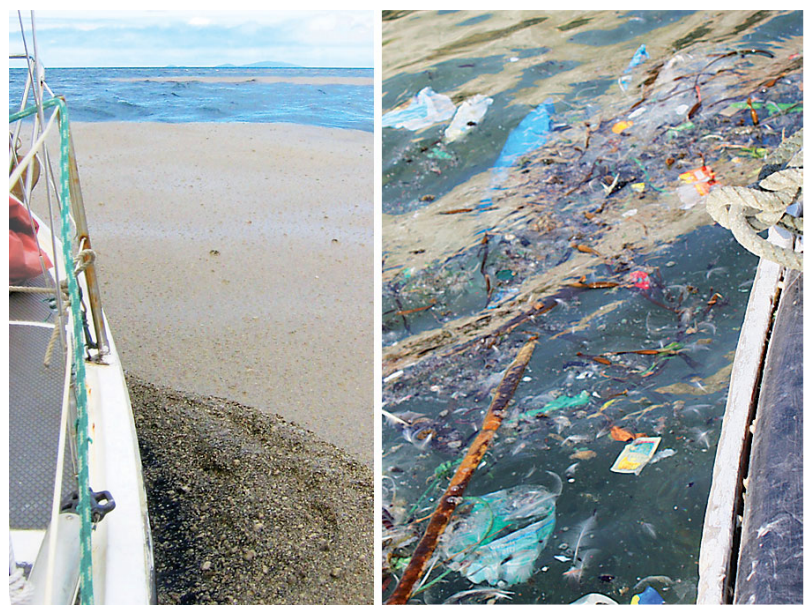

Dispersal of organisms across the oceans is brought about by dense aggregations of pumice (left), which may appear sporadically after submarine volcanic eruptions, and by ubiquitous accumulations of anthropogenic debris (right).

Photos: A. van den Broek, S. Bryan (left); M. Thiel (right)

KEY WORDS: Rafting - Abiotic substrata - Surface rugosity · Buoyancy · Floating behaviour · Fouling community $\cdot$ Succession $\cdot$ Chile

Resale or republication not permitted without written consent of the publisher

\section{INTRODUCTION}

During the past few decades, the abundance and frequency of occurrence of abiotic substrata has increased drastically in the oceans, mainly as a result of massive amounts of plastic entering the sea (Barnes et al. 2009). Increasing abundances of abiotic 
substrata of anthropogenic origin are reason for concern because they might result in a drastic shift of dispersal opportunities on these long-lasting floating objects (Gregory 2009).

In the marine environment, floating substrata (natural and anthropogenic) are ubiquitous dispersal agents for a wide diversity of different organisms. The properties of floating substrata are thought to determine the pool of organisms that might be transported on them (Thiel \& Gutow 2005a,b). Even though this relationship has been known for a long time, surprisingly little is known of how substratum characteristics affect the diversity of biota on floating substrata. This is particularly true for organisms associated with abiotic floating items, which can be very abundant in specific areas (Thiel \& Gutow 2005a) or at certain time periods (Bryan et al. 2004).

Some of the most relevant properties of abiotic substrata in the context of rafting are their chemical and physical composition, which determine their buoyancy and longevity at the sea surface. Substrata such as volcanic pumice and Styrofoam have numerous small inclusions of air bubbles, allowing them to float at the sea surface (e.g. Jokiel 1989). Similarly, many plastic items enclose large volumes of air, conferring them extraordinarily high buoyancy. Most of these abiotic substrata are also very resistant to decay. Due to their inorganic nature, they offer no or only minimal food value to most marine organisms, and therefore resist biotic attacks (albeit small items may be swallowed by seabirds and other organisms; e.g. Laist 1987, Ryan et al. 2009). Even though abiotic substrata are prone to degradation by exposure to light (Andrady et al. 1993), temperature variations (Thiel \& Gutow 2005a), and abrasion (in the case of pumice) (Risso et al. 2002), their decay rates in sea water are usually slow, i.e. these substrata persist for many months, often more than a year (Pegram \& Andrady 1989). Due to these properties (buoyancy and resistance to decay), abiotic substrata survive much longer at the sea surface than most biotic floating substrata, e.g. algae and wood (Thiel \& Gutow 2005a). This high longevity makes abiotic substrata a potential transport vector for long distance dispersal of organisms that can hold onto and do not depend on them for food.

While there are important similarities (e.g. longevity) among abiotic floating substrata, they also differ in some characteristics that are relevant in the context of species colonization and rafting. Surface rugosity, known to affect settlement and survival of sessile organisms (Dudley \& D'Antonio 1991, Wahl \& Hoppe 2002, Faimali et al. 2004, Granhag et al. 2004), may differ substantially among substrata. Moderate rugosity facilitates colonization because propagules find better substratum adhesion in surface depressions (Granhag et al. 2004) or protection against grazers (Wahl \& Hoppe 2002, Hutchinson et al. 2006). Buoyancy can also affect colonization by fouling organisms. For example, Styrofoam has very high buoyancy, and therefore most of its surface will be exposed to air, which might negatively influence the success of initial colonizers. Another characteristic, rarely taken into account, is floating stability at the sea surface. Sailors are well acquainted with the importance of floating stability: when the boat turns over its passengers are exposed to the surrounding water, while any organisms growing on the underside of the boat get exposed to the air. Many marine organisms, and in particular early benthic stages, are susceptible to repeated or prolonged exposure to air (e.g. Benedetti-Cecchi et al. 2006), and consequently the stability of a floating item at the sea surface may affect the composition of the communities developing on them.

Most of our present knowledge on organisms that are transported on abiotic floating substrata comes from items found on the shore. Often these items have been deposited on the beach long before being collected for scientific analysis. Thus, while we have relatively good information on sessile species such as corals, oysters, barnacles, and bryozoans being transported on volcanic pumice (Jokiel 1984, 1989, 1990) or plastics (Barnes 2002, Barnes \& Milner 2005), we know relatively little about other organisms, let alone the succession processes of the floating community on these abiotic floating substrata.

Succession of benthic communities on hard substrata is mainly related to the occurrence of disturbances, arrival of colonists, and species interactions (e.g. Connell \& Slatyer 1977, Platt \& Connell 2003, Underwood \& Chapman 2006). A number of studies have also explored the importance of substratum rugosity, which can influence initial settlement and survival of colonists (Wahl \& Hoppe 2002, Faimali et al. 2004, Granhag et al. 2004, Hutchinson et al. 2006). However, rugosity effects mainly appear during very initial stages but lose relevance during later stages of community succession (e.g. Bers \& Wahl 2004, Scardino \& de Nys 2004, Totti et al. 2007). While rugosity may thus only be important at the beginning of community succession on floating substrata, buoyancy and floating behaviour may significantly affect substratum stability and, thereby, community succession throughout the floating period. Frequent exposure of substrata to air, either due to high buoyancy or 
because they frequently turn over (or both), may repeatedly lead to high mortality and disappearance of fouling organisms. Consequently, community succession on highly buoyant and unstable substrata might be arrested in initial successional stages, where only stress-tolerant colonizers can survive, similar to benthic communities under conditions of extreme air exposure (e.g. Benedetti-Cecchi et al. 2006).

In order to evaluate the role of abiotic floating substrata as dispersal agents for marine organisms, we conducted a series of samplings and experiments to (1) determine the floating properties of 3 different abiotic substrata (pumice, plastics, and Styrofoam), and (2) to examine how these properties affect species colonization and community succession on each substratum. Specifically, we predicted that species richness would initially be highest on the substratum with the highest surface rugosity, that communities were most diverse on the least buoyant substratum, and that opportunistic colonizers dominated on the substratum that most frequently changed position at the sea surface. These predictions were tested by exposing floating substrata to natural colonization by fouling organisms in coastal waters of northerncentral Chile.

\section{MATERIALS AND METHODS}

\section{Study site}

Colonization experiments were conducted between August and December 2006 in Bahía La Herradura (Coquimbo), a semi-enclosed bay on the northerncentral coast of Chile (Fig. 1a). Water temperatures in the bay vary between $13^{\circ} \mathrm{C}$ in winter and $20^{\circ} \mathrm{C}$ in summer (Moraga \& Olivares 1993). The sea floor at the study site is characterized by soft sediments at 7 to $8 \mathrm{~m}$ from the water surface. There are numerous artificial structures in the bay (buoys, piers, suspended culture systems, and other marine facilities) that are colonized by a diverse fouling community (for more details of the study system see Valdivia et al. 2005, Cifuentes et al. 2007).

\section{Floating substrata and their properties}

Three types of abiotic substrata were used in the colonization experiments: volcanic pumice, plastic jars, and Styrofoam pieces (Fig. 1b), all of an approximate volume of 40 to $70 \mathrm{ml}$. In the case of the plastic jars and Styrofoam pieces, these were chosen to be of

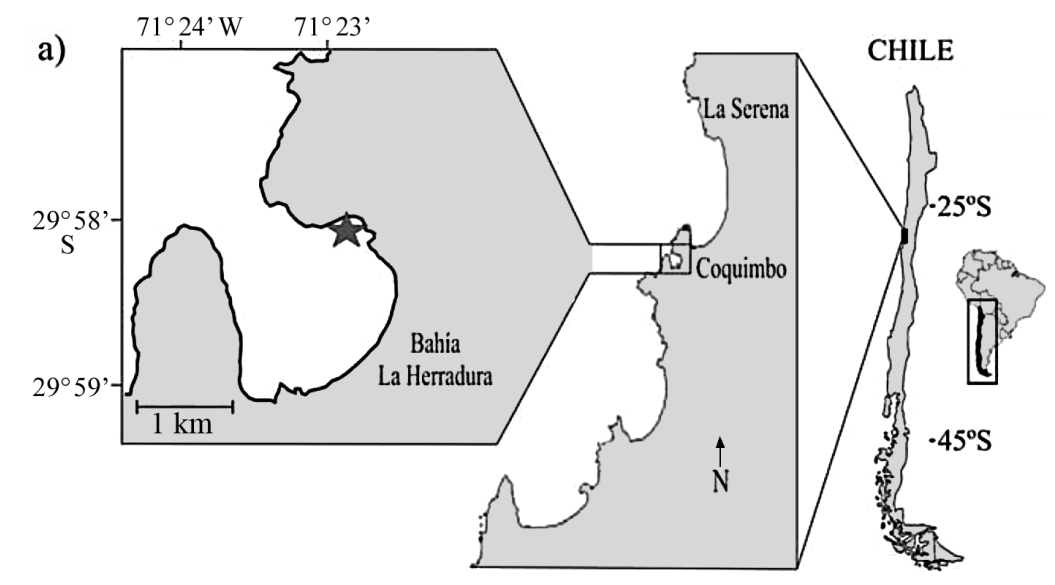

b)

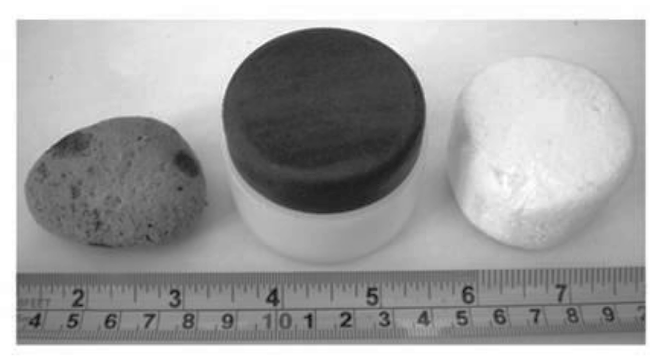

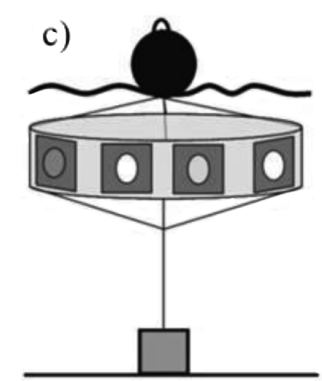

Rings

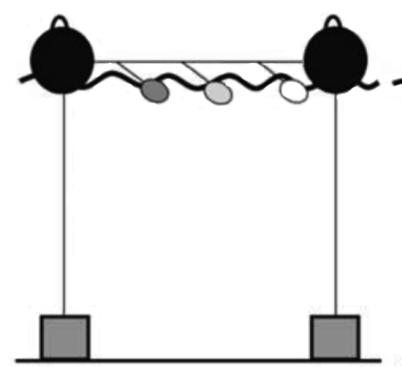

Lines

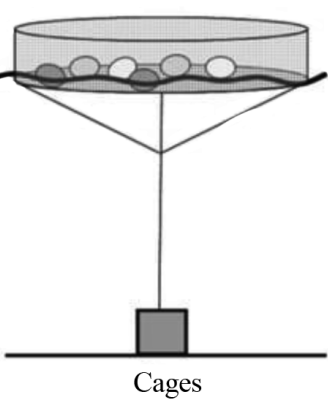

Fig. 1. (a) Study site; exact location where the experiments were carried out is shown with a star. (b) The 3 abiotic substrata (left to right: pumice, plastic, Styrofoam). (c) Experimental set-up for the 3 colonization experiments 
similar sizes as the pumice pieces commonly found on beaches of the Chilean coasts. The dimensions of the plastic jars were $5 \mathrm{~cm}$ diameter $\times 4 \mathrm{~cm}$ high, while the Styrofoam pieces were $5 \mathrm{~cm}$ in diameter $\times 2.5 \mathrm{~cm}$ high. In order to gain a better understanding of the factors driving the colonization process, we characterized the substratum properties according to their floating duration, surface features, buoyancy, and floating stability.

Floating duration. A total of 20 replicates of each substratum was placed in a $300 \mathrm{l}$ tray with flowing seawater for $1000 \mathrm{~d}$. This time period was chosen because the floating duration of many abiotic substrata is known to exceed 1 yr. Every 1 to 3 d, we surveyed whether substrata remained floating. Some objects were lost from the tray due to unknown reasons (2 pieces of pumice at $193 \mathrm{~d}$ and $287 \mathrm{~d}, 1$ piece of plastic at $287 \mathrm{~d}$ ). The total number of substrata remaining in the tray at the end of the experiment was considered as $100 \%$.

Surface rugosity. A total of 10 replicates of each substratum was photographed with a dissecting microscope, using lateral lights for better contrast of the surface relief. Images were analyzed with the program Image-Pro Plus 4.5 (Media Cybernetics) with the purpose of identifying and counting rugosities. The images of the substrata were transformed to B\&W (black \& white) contrasts. The ranges of threshold values for this $\mathrm{B} \& \mathrm{~W}$ transformation depended on substratum type: pumice was in a range of 120 to 155 , plastics 85 to 115, and Styrofoam 165 to 200 . All rugosities within an area of $1 \mathrm{~cm}^{2}$ were counted, and their individual area was measured. In the case of pumice and Styrofoam, depressions in the substratum were considered as rugosities (the contiguous surface is interrupted by depressions). In plastics, protuberances on the substratum were considered as rugosities (contiguous surface is interrupted by elevated scratches and small grains). We calculated for each replicate the total rugosity area as the sum of all individual areas.

Substratum buoyancy. A total of 20 replicates of each substratum was placed individually in a graduated cylinder topped with seawater. Before placing it in the water, each object was weighed $(0.1 \mathrm{~g}$ accuracy). The cylinder was placed in a plastic tray to retain the water that was displaced after putting the floating substratum in the cylinder. The total volume was calculated using the volume of water displaced after submerging the entire object. Substratum buoyancy was thus defined as the inverse of the percentage of the object below the water surface. Higher percentages of submerged volume of a replicate represented lower substratum buoyancy.
Floating stability. A total of 20 replicates of each substratum was placed individually in a tray $(37 \mathrm{~cm}$ long $\times 29 \mathrm{~cm}$ wide $\times 17 \mathrm{~cm}$ high) filled with $10 \mathrm{l}$ of seawater. The tray was then agitated to produce waves. Following this agitation, we waited until the water surface and the floating item had completely calmed down. The side of the floating object that was facing upwards (i.e. the highest point) was marked with a permanent marker pen, and recorded as one position. This procedure was repeated 100 times for each of the 20 replicates from a substratum type. For each replicate, we registered the number of times that it changed position, the number of positions it adopted, and the frequency of occurrence of these positions.

\section{Colonization of substrata}

We conducted 3 colonization experiments in the field in order to test the effects of substratum properties on the colonization process. We used a randomized block design with replication for each experiment. In the first experiment (Rings), substrata were permanently suspended (about $1 \mathrm{~m}$ below the sea surface) to examine the effects of surface rugosity on the colonization process. In the second experiment (Lines), substrata were attached to lines that held the substrata at the sea surface, restricting the overturn of substrata, to examine the effects of buoyancy (proportion of the substratum below the sea surface) on colonization. And in the last experiment (Cages), substrata were maintained in cages, allowing them to overturn freely to examine the effects of floating stability on the colonization process.

The 3 colonization experiments lasted $98 \mathrm{~d}$ each. This duration was chosen because previous studies had suggested that rafting communities experience important changes during this time period (Ye \& Andrady 1991, Tsikhon-Lukanina et al. 2001). The developing fouling communities were surveyed at regular intervals $(2,4,6,8,10$, and 14 wk after the start of the experiment). At each sampling date, we estimated the \% cover of each sessile species, and we determined the taxonomic richness on each replicate. All experiments started in August 2006 and ended in November 2006, with the last sampling after 14 wk of exposure.

Surface rugosity (Rings). In this experiment we tested the effect of substratum rugosity ( 3 levels: pumice, plastic, or Styrofoam) on community succession. Blocks consisted of $6 \mathrm{PVC}$ rings $(60 \mathrm{~cm}$ diameter $\times 25 \mathrm{~cm}$ height $\times 0.3 \mathrm{~cm}$ thick) that were individually 
suspended $1 \mathrm{~m}$ below the sea surface (Fig. 1c). Nine PVC panels $(15 \mathrm{~cm} \times 15 \mathrm{~cm} \times 0.3 \mathrm{~cm})$ were fixed to the inner surface of each PVC ring with cable ties. We glued a layer ( 4 to $5 \mathrm{~cm}$ diameter) of 1 of the 3 substrata to the centre of each panel with non-toxic adhesive (for a similar set-up, see also Totti et al. 2007). The 3 substratum levels with 3 replicates each were randomly allocated to panels. Pumice and Styrofoam layers were prepared by cutting sheets of $\sim 1 \mathrm{~cm}$ thickness. We used the lids of the jars as plastic substrata, which resulted in a height of $\sim 1 \mathrm{~cm}$ above the PVC panel. Since panels were at a fixed depth and orientation within rings, we were able to keep buoyancy and floating stability constant across substrata, and to focus on the differences in substratum rugosity.

Buoyancy (Lines). We tested the effects of substratum buoyancy and face of the substrata (3 levels: upper face, lower face, and side) on successional patterns of fouling communities. In this experiment, blocks consisted of five $6 \mathrm{~m}$ long lines (Fig. 1c), fixed at $\sim 10 \mathrm{~cm}$ below the sea surface. We tethered 4 replicates of each substratum in random order along the line, at distances to each other that impeded direct contact. Substrata were attached with a nylon thread and a spindle that allowed the object to rotate freely around the axis of the spindle. The nylon threads, which held the substrata on the lines, ensured that substrata did not turn over. Thus, this experiment allowed us to keep floating stability constant across different substrata and to focus mainly on the effects of buoyancy.

Floating stability (Cages). To examine how floating stability and face of the substrata affected colonization, freely floating substrata were placed in large mesh cages (i.e. blocks), which allowed the substrata to turn over naturally. Five cylindrical cages $(67 \mathrm{~cm}$ diameter $\times 35 \mathrm{~cm}$ high), made of $1 \mathrm{~cm}$ rigid plastic mesh, were anchored at the sea surface (Fig. 1c). Three swimmers (small plastic bottles of $500 \mathrm{ml}$ volume each) were attached to the side of each cage in order to keep it semi-submerged. Each cage held 4 replicates of each substratum.

\section{Surveys of the developing communities}

At each sampling date all experimental units were brought to shore. The substrata were carefully retrieved or detached from their holding structures and placed in trays with seawater. Care was taken that substrata were constantly protected against direct sun exposure. There is no indication that handling affected the species composition of the developing communities (see also Valdivia et al. 2005, Cifuentes et al. 2007).

Each replicate was then individually surveyed. Taxonomic richness and \% cover of sessile species was estimated with the aid of a dissecting microscope. All taxa were identified to the lowest possible taxonomic level. Organisms identified up to genus and showing minimal morphological differences were grouped under the species epithet 'sp'. The \% cover of each sessile macrobenthic species (>1 mm) was estimated using a quadrat of an area of ca. $3 \times$ $3 \mathrm{~cm}$ on each face of the substratum. This area was selected because all 3 substrata had an approximate surface area of $5 \times 5 \mathrm{~cm}$, thus leaving about $1 \mathrm{~cm}$ on each side of the survey quadrat in order to avoid edge effects. Percentage cover was estimated at $5 \%$ intervals, and species covering less than $5 \%$ were recorded as $1 \%$. Due to the multilayered structure of the community, total cover could exceed $100 \%$, but cover of a single species had a maximum of $100 \%$.

On the substrata in the Rings experiment, we estimated the species cover on the surface that was exposed to colonization (see also Totti et al. 2007). In contrast, on the floating substrata in the Lines and Cages experiments, which could be colonized on all faces, we surveyed 3 faces on each replicate: (1) lower face, (2) upper face and (3) side. These faces were permanently marked to re-identify them in subsequent samplings.

\section{Statistical analyses}

Surface rugosity, buoyancy, and floating stability. We used separate 1-way ANOVAs to test the effect of substratum (fixed factor with 3 levels: pumice, plastic, or Styrofoam) on total rugosity area, percentage of volume below water, and number of changes of position. In addition, persistence of substrata in each position was assessed with contingency tables.

Colonization. In all 3 experiments (i.e. Rings, Lines, and Cages), taxonomic richness and \% cover were analyzed as dependent variables. Each experiment was analyzed separately as a split-plot ANOVA arranged in randomized blocks. Each replicate piece was considered as a plot. Either time (Rings experiment) or face (Lines and Cages experiments) were the splits. For the Rings experiment, we used a 3-way mixed model ANOVA with substratum as betweenplot and fixed factor, block as between-plot and random factor, and time (6 levels) as within-plot and fixed factor. 
For the Cages and Lines experiments, only data from the last sampling date were analyzed in order to simplify interpretation of interactive effects; this is also justified because we were mainly interested in the suitability of these substrata as long-distance dispersal vehicles, i.e. colonization patterns after long time periods (here $14 \mathrm{wk}$ ) at the sea surface. We used 3-way ANOVAs with substratum and block as described in the previous paragraph, and face (3 levels: upper face, lower face, side) as within-plot and fixed factor. Some replicates were lost from the Line experiment due to wave action and bird attack. In that case, we randomly removed replicates from the analysis until all groups had the same n. Since in some cases the variancecovariance matrices were not spherical (Mauchly's test for sphericity; $\mathrm{p}<0.001$ ), we adjusted the degrees of freedom of the within-subject factors with the Greenhouse-Geisser epsilon (Quinn \& Keough 2002).

Prior to all ANOVAs (i.e. analyses of substratum properties and colonization), data were graphically explored to determine appropriate transformations. After data exploration, homogeneity of variances was formally tested with Levene's test. Data were arcsine, $\log _{10}$, or rank transformed when needed. Tukey's HSD was used as post hoc test after ANOVAs.

We conducted multivariate analyses to test the effects of substratum on community composition. Separate analyses of similarity (ANOSIM) based on Bray-Curtis dissimilarities were conducted for each experiment, sampling date, and substratum. Data were presence-absence transformed before ANOSIM. Univariate analyses were conducted in R environment version 2.11.1 (R Development Core Team 2011), and ANOSIMs were conducted with PRIMER version 5.

\section{RESULTS}

\section{Substratum properties}

Floating duration. After $1000 \mathrm{~d}$ in the seawater tray, 14 pieces (out of the 18 replicate pieces) of volcanic pumice had sunk. The first pumice sank after $161 \mathrm{~d}$, the second after $332 \mathrm{~d}$, the third after $503 \mathrm{~d}$, the fourth after $523 \mathrm{~d}$, the fifth after $541 \mathrm{~d}$, and the sixth after $635 \mathrm{~d}$. Most pumice pieces sank between 500 and $750 \mathrm{~d}$ (Fig. 2). After $554 \mathrm{~d}$, one piece of pumice split in 2 pieces, and was removed from the tray. At the end of the experiment $(1000 \mathrm{~d})$ all 20 Styrofoam pieces and the 19 plastics continued floating (Fig. 2).
Surface rugosity. There were significant differences among the 3 substratum types in terms of rugosity (total area of rugosities) (1-way ANOVA: $\left.F_{2,26}=8.758, \mathrm{p}<0.001\right)$. Pumice had a higher surface rugosity compared with the other 2 substrata (Tukey's HSD, $\mathrm{p}<0.001$ ). There were no significant quantitative differences between plastic and Styrofoam rugosity (Tukey's HSD, p > 0.05). However, in the Styrofoam the continuous surface area was interrupted by surface depressions, while in the plastics the continuous area was interrupted by surface protuberances. SEM images confirmed those differences in surface rugosity between the 3 types of substrata. Volcanic pumice had a very irregular surface with numerous cracks and porosities (Fig. 3a). The plastics had a very smooth surface, without any cracks or cavities (Fig. 3a). The surface of the Styrofoam was irregular, made up of layers of material that formed some depressions and ridges (Fig. 3a).

Substratum buoyancy. The mean percentage of volume below water significantly differed among the 3 substratum types (1-way ANOVA on rank-transformed data: $\left.F_{2,57}=306.86, \mathrm{p}<0.001\right)$. A large proportion of the volume of clean pumice was submerged. This percentage was much higher than for the other 2 substratum types. Only $\sim 15 \%$ of the volume of the plastic pieces was submerged, and in the Styrofoam pieces this proportion is $<0.5 \%$ (Fig. $3 b$ ). Accordingly, all pairwise comparisons showed significant differences (Tukey's HSD test, $\mathrm{p}<0.001$ ). The density of pumice was substantially higher than that of the plastics and in particular of Styrofoam, which had an extremely low density (Table 1).

Floating stability. The 3 types of floating objects significantly differed in terms of number of positional changes (1-way ANOVA on rank-transformed data: $\left.F_{2,57}=96.71, \mathrm{p}<0.001\right)$. Styrofoam changed floating position significantly more often than pumice and 
a)

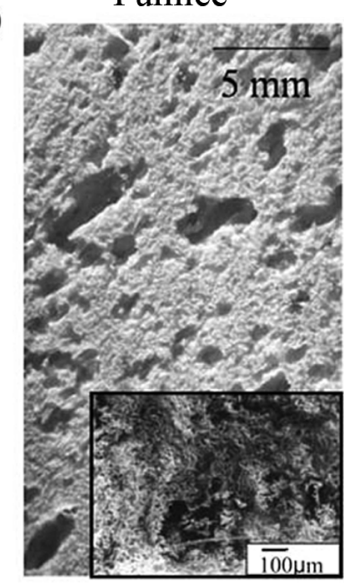

b)

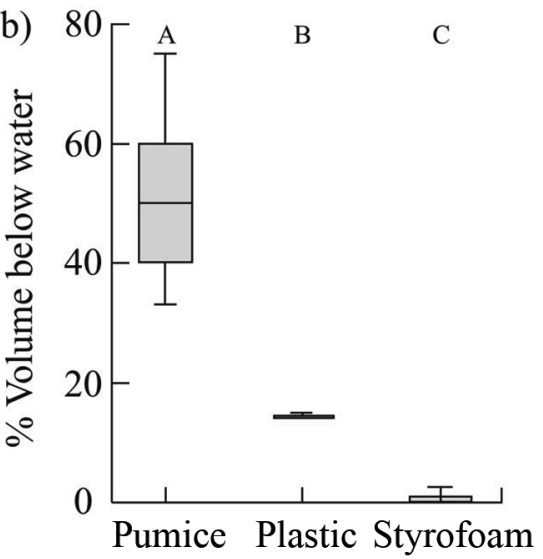

Plastic

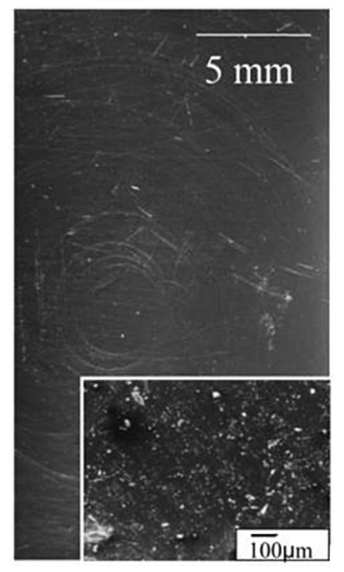

c) 80

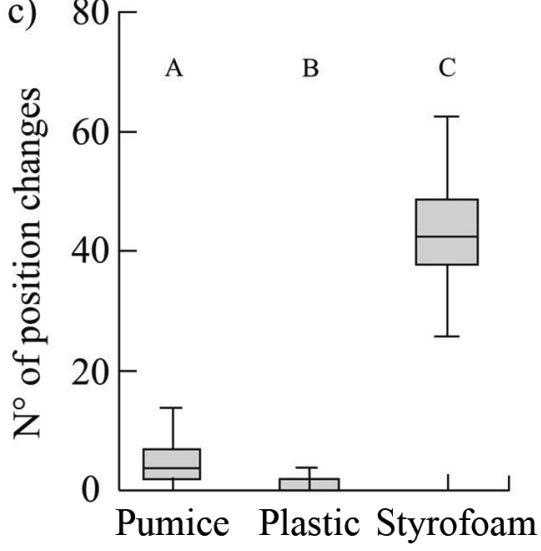

Fig. 3. (a) Light microscope images and SEM-images (inset) of the 3 abiotic substrata. (b) Total \% of submerged volume of each substratum type. (c) Number of positional changes of the 3 substrata after 100 agitations in a small tank. Box plots show the median (line in box), 25 and $75 \%$ quartiles (ends of the box), and extreme values within 1.5 box length (whiskers); different letters above the boxes indicate significant differences after Tukey's HSD post hoc test, $\mathrm{p}<0.05$

plastics, and pumice more often than plastics (Fig. 3c; Tukey's HSD, $\mathrm{p}<0.001$ ). There were also significant differences in the number of positions adopted by the different objects $\left(\chi_{(2)}^{2}=19.1 ; p<0.001\right)$. Four pumice pieces had only one single stable position, while the

Table 1. Density \pm SD and floating stability (permanence in a determined position; $\% \pm 95 \%$ binomial confidence intervals of occasions that the objects adopted position 1 or position 2) of the 3 abiotic floating substrata. The experiment was carried out with 20 items of each substratum. Each item was agitated 100 times

\begin{tabular}{|lccc|}
\hline Substrata & $\begin{array}{c}\text { Density } \\
\left(\mathrm{g} \mathrm{cm}^{-3}\right)\end{array}$ & \multicolumn{2}{c|}{ Ploating stability } \\
& \multicolumn{1}{c}{ Position 1 (\%) } & Position 2 (\%) \\
\hline Pumice & $0.56 \pm 0.10$ & $75(50.6-90.4)$ & $25(0.3-49.4)$ \\
Plastic & $0.17 \pm 0.005$ & $99(73.1-99.7)$ & $1(0.03-26.9)$ \\
Styrofoam & $0.04 \pm 0.009$ & $56(32.0-76.1)$ & $44(23.8-67.9)$ \\
\hline
\end{tabular}
Styrofoam in the cages) (Table 2). There were taxa that prevailed in one experiment more than in another. Obelia sp. 1 and Austromegabalanus psittacus were predominant on the rings, while Ectocarpales, Polysiphonia spp., and Bugula neritina prevailed on the lines. Some species that were common on the lines or abundant in the cages (e.g. Scytosiphon lomentaria) did not occur on the rings (Table 2). At the end of the experiment (after $14 \mathrm{wk}$ ), the highest number of taxa was observed in the cages on plastics (22 taxa) and on pumice (19), and in the lines on the plastics (19) (Table 2). The lowest taxon richness was observed on Styrofoam in both the cages (7) and on the rings (12).

Surface rugosity (Rings). On all 3 substrata, a gradual increase in taxonomic richness occurred during the first 2 mo. But, after reaching a peak in Week 8, the number of taxa decreased again, particularly on 
Table 2. Frequency of occurrence of species on each substratum (pumice, plastic, Styrofoam) in the 3 field experiments (Rings, Lines, Cages) during the last survey (Week 14)

\begin{tabular}{|c|c|c|c|c|c|c|c|c|c|}
\hline & \multicolumn{3}{|c|}{ Rings } & \multicolumn{3}{|c|}{ Lines } & \multicolumn{3}{|c|}{ Cages } \\
\hline & Pumice & Plastic & Styrofoam & Pumice & Plastic & Styrofoam & Pumice & Plastic & Styrofoam \\
\hline $\mathrm{n}$ & 20 & 20 & 20 & 10 & 16 & 9 & 21 & 20 & 20 \\
\hline Diatoms & 95 & 85 & 100 & 50 & 100 & 89 & 76 & 100 & 95 \\
\hline Ulvales & 90 & 45 & 70 & 100 & 100 & 100 & 100 & 95 & 95 \\
\hline Ectocarpales & 5 & - & - & 70 & 50 & 44 & 19 & 10 & 25 \\
\hline Rhodophytas & 5 & - & - & - & - & - & - & 35 & - \\
\hline Scytosiphon lomentaria & - & - & - & 20 & 19 & 11 & 52 & 55 & 5 \\
\hline Petalonia sp. 1 & - & - & - & - & - & - & 14 & 20 & 5 \\
\hline Red frond & - & - & - & - & - & 22 & - & - & - \\
\hline Antithamnion sp. 1 & 5 & 15 & 20 & - & - & - & - & 10 & - \\
\hline Polysiphonia spp. & 55 & 55 & 50 & 80 & 75 & 44 & 10 & 25 & - \\
\hline Ceramiales & 10 & 5 & 5 & - & - & 11 & 29 & 10 & 20 \\
\hline Crustose coralline & 5 & - & - & - & 13 & - & - & 15 & - \\
\hline Chlorophyta indet. & - & - & - & - & - & 44 & - & 5 & 40 \\
\hline Ochrophyta indet. 1 & - & - & - & - & 6 & - & - & - & - \\
\hline Hydrozoa sp. 1 & - & - & - & - & - & - & - & 10 & - \\
\hline Hydrozoa sp. 2 & - & - & - & - & - & - & 5 & 10 & - \\
\hline Hydrozoa sp. 4 & - & - & - & - & 6 & - & - & 25 & - \\
\hline Obelia sp. 1 & 95 & 100 & 100 & - & 56 & - & 38 & 45 & - \\
\hline Tubularia sp. 1 & - & - & - & 10 & 6 & 11 & 33 & 40 & - \\
\hline Plumularia sp. 1 & 5 & 5 & 5 & - & - & - & - & - & - \\
\hline Balanus spp. & - & - & - & - & - & - & 5 & 5 & - \\
\hline Austromegabalanus psittacus & 20 & 95 & 25 & - & 6 & 11 & - & - & - \\
\hline Lepas pectinata & - & - & - & - & - & 11 & 5 & - & - \\
\hline Lepas spp. & - & - & - & 10 & - & - & 5 & - & - \\
\hline Membranipora isabelleana & - & 5 & - & 40 & 6 & 11 & 48 & - & - \\
\hline Bugula neritina & - & 10 & 15 & 90 & 56 & 44 & 14 & 65 & - \\
\hline Bugula flabellata & - & - & - & 10 & 6 & - & 5 & 45 & - \\
\hline White Bugula & - & - & - & 10 & 6 & - & - & - & - \\
\hline Diplosoma sp. 1 & 65 & 85 & 70 & 100 & 81 & 44 & 76 & 85 & - \\
\hline Ciona intestinalis & 20 & 10 & 10 & 30 & 6 & 11 & 14 & 45 & - \\
\hline Pyura chilensis & 45 & 50 & 50 & 30 & 63 & 22 & 14 & 70 & - \\
\hline Nudibranchia egg mass & 5 & 5 & - & - & 13 & - & - & - & - \\
\hline Total number of species & 15 & 14 & 12 & 14 & 19 & 16 & 19 & 22 & 7 \\
\hline
\end{tabular}

plastics and Styrofoam (Fig. 4). Accordingly, the ANOVA suggests that the 3 substrata responded differently over time (time $\times$ substratum, $\mathrm{p}=0.001$, Table S1 in the supplement at www.int-res.com/ articles/suppl/m439p001_supp.pdf). Inspection of means and Tukey's HSD post hoc tests conducted for each sampling date showed that taxonomic richness on plastic substrata was significantly lower than on pumice and Styrofoam in Week 2, and higher than pumice in Week 10. No significant differences among substrata were evident at all other sampling dates. We also detected that blocks (= rings) varied differently over time in terms of taxonomic richness (time $\times$ block, $\mathrm{p}<0.001$, Table $\mathrm{S} 1$ in the supplement). The differences among blocks, however, did not influence the differences between substrata over time (time $\times$ block $\times$ substratum, $\mathrm{p}=0.742$, Table $\mathrm{S} 1$ in the supplement).
Total \% cover significantly varied over time and across substrata (Fig. 5; time $\times$ substratum, $\mathrm{p}<0.001$, Table S1 in the supplement). Tukey's HSD post hoc tests conducted for each sampling date showed that total \% cover on plastic substrata was significantly lower than on pumice and Styrofoam in Week 2, and higher than pumice and Styrofoam in Weeks 10 and 14. No other significant differences between substrata were found. On the other hand, block effects on total \% cover also varied significantly over time (time $\times$ block, $\mathrm{p}=0.002$, Table $\mathrm{S} 1$ in the supplement), but this effect did not influence the differences between substrata (time $\times$ block $\times$ substratum, $\mathrm{p}=$ 0.094, Table S1 in the supplement).

In the first 2 wk of the experiment, diatoms dominated on all 3 substrata. Also the hydrozoan species 1 was very common, but then disappeared and was not found thereafter. Starting in Week 6, the com- 

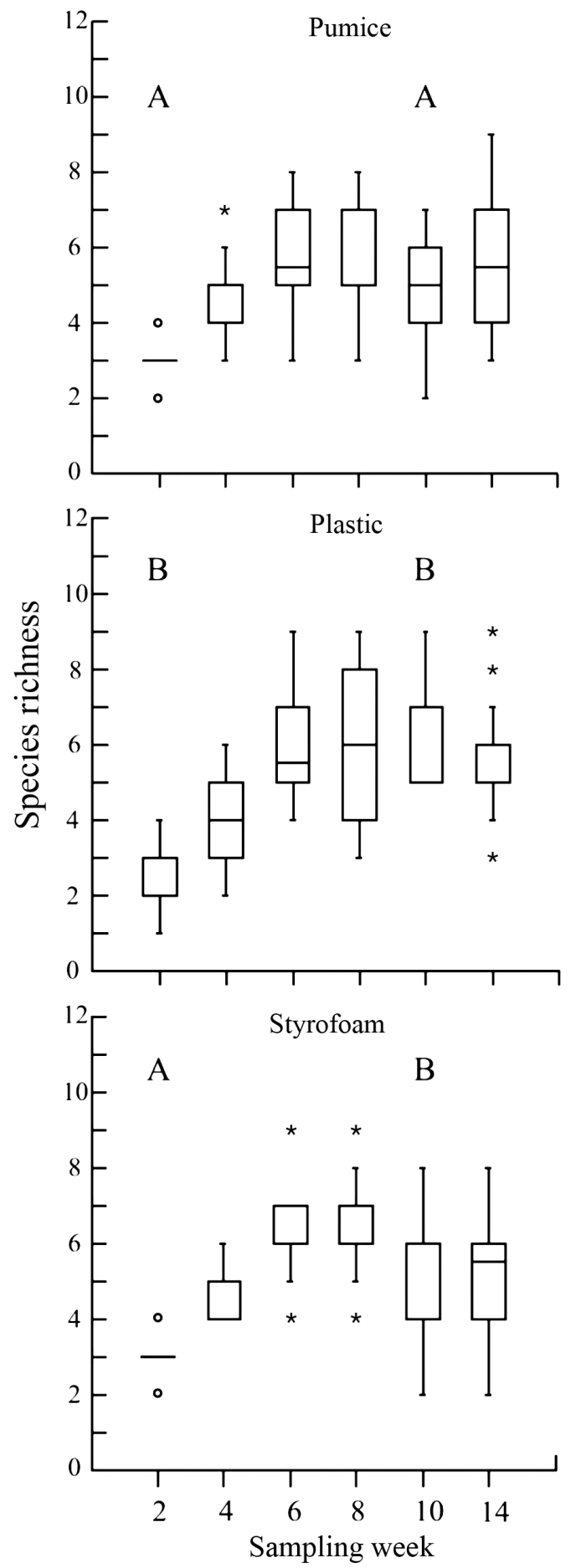

Fig. 4. Species richness on pumice, plastic, and Styrofoam plates on the rings during the different sampling dates; box plots show the median (line in box), 25 and $75 \%$ quartiles (ends of the box), and values within 1.5 box length (whiskers). $\left({ }^{*}\right)=$ outliers and $(\circ)=$ extreme values. Significant differences (Tukey's HSD, $p<0.05$ ) between substrata in a given week are indicated by different uppercase letters. In the weeks where there are no letters, no significant differences were found among the 3 substrata (comparisons between substrata need to be viewed in vertical direction)
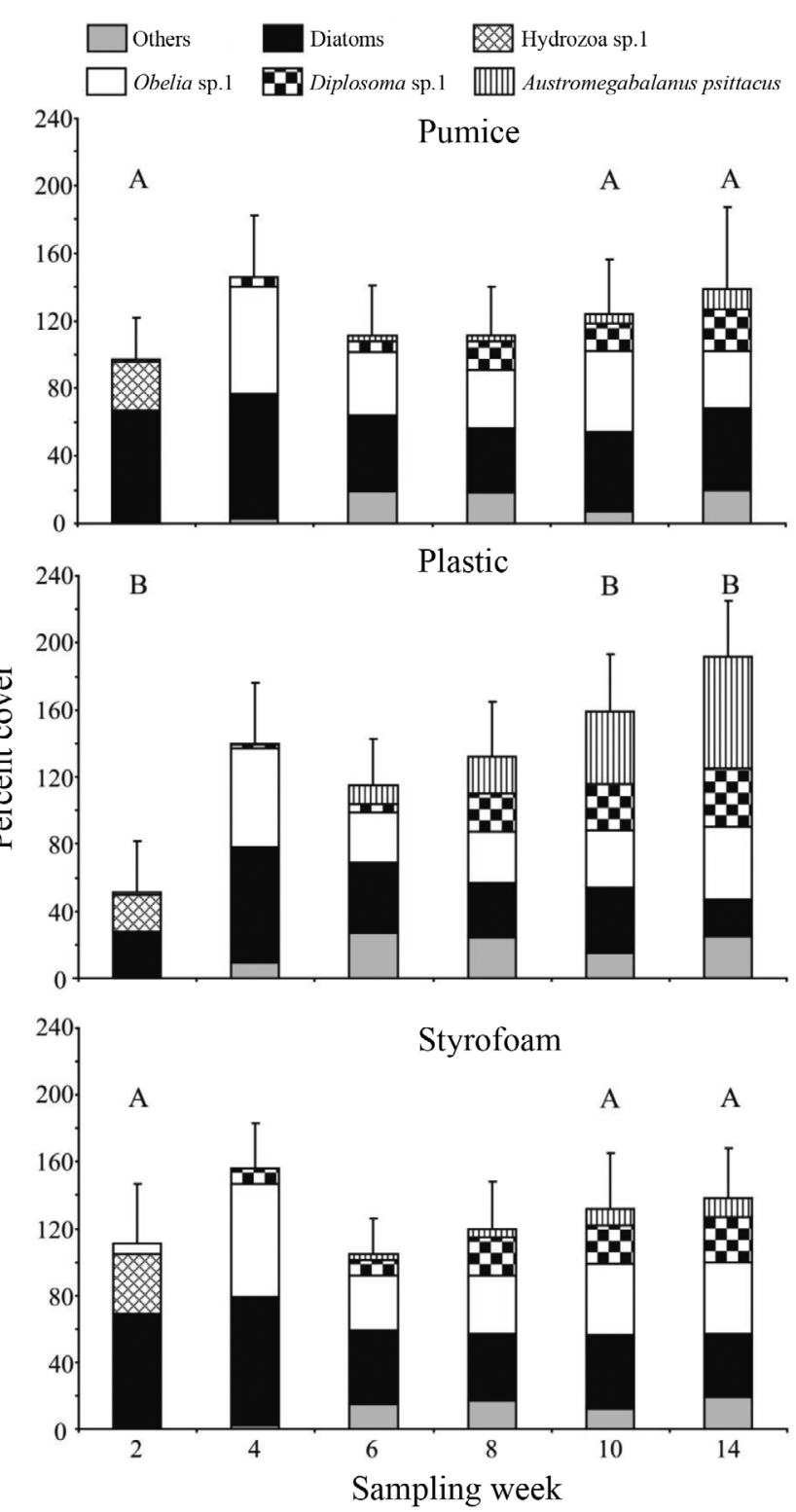

Fig. 5. Total \% cover and community composition on pumice, plastic and Styrofoam plates on the rings during the different sampling dates. See Fig. 4 for further explanations

munities of all 3 substrata were dominated by diatoms, Obelia sp. 1, Austromegabalanus psittacus, and Diplosoma sp. 1, and there were no major differences among the substrata, with the exception of $A$. psittacus, which began to show a predominance on the plastics starting in Week 10 (Fig. 5).

The ANOSIM showed that the community structure on plastics differed significantly from that on pumice and Styrofoam during Weeks 2 and 14 ( $\mathrm{p}=$ 0.001, Table S2 in the supplement). Between plastic and pumice, these significant differences first appeared in Week $10(p=0.012)$. Throughout the entire 
experiment, no significant differences were found between pumice and Styrofoam ( $p>0.05)$. During the first 2 and last 2 samplings, significant differences were found between some pairs of rings, yet these differences were not consistent (Table $\mathrm{S} 2$ in the supplement).

Buoyancy (Lines). Starting in Week 4, numerous replicates of this experiment, mainly Styrofoam and pumice, were lost due to storms, seabirds, and sinking. The highest losses were recorded in Styrofoam, where a total of 11 (out of 20) replicates disappeared during the experiment, mainly due to destruction by seabirds. During the last sampling date (Week 14), 3 pieces of pumice sank.

Analyses conducted on 14 wk old assemblages showed that taxonomic richness significantly varied between substrata (Fig. 6, p $=0.018$, Table S2 in the supplement) and this effect was independent of blocks (block $\times$ substratum, $p=0.457$ ) and faces (face $x$ substratum, $p=0.098)$. No main effect of face was found $(p=0.153)$. Species richness was higher on pumice than on plastic substratum (Tukey's HSD, $\mathrm{p}=$ 0.036) but there were no significant differences between either pumice and Styrofoam (Tukey's HSD, $\mathrm{p}=0.082$ ) or plastic and Styrofoam (Tukey's HSD, $\mathrm{p}=$ 0.999).

Similarly, total \% cover significantly varied between substrata $(\mathrm{p}<0.001$, Table S1 in the supplement). This effect was independent of block (block $x$ substratum, $\mathrm{p}=0.567$ ) and face (face $\times$ substratum, $p=0.118)$. We found no significant differences between faces $(p=0.118)$. Inspection of means and $a$ posteriori comparisons showed that assemblages developing on pumice covered a significantly larger percentage of substratum than assemblages developing on plastic and Styrofoam (Fig. 7, Tukey's HSD, $\mathrm{p}<0.001$ ).

In the first $2 \mathrm{wk}$, diatoms dominated on all 3 substrata. Ulvales, Obelia sp. 1, and Diplosoma sp. 1 appeared in Week 4 on the pumice where they persisted until the end of the experiment, with the Ulvales becoming dominant after Week 6 . On the plastics, Ulvales and Obelia sp. 1 appeared in Week 4 and stayed during the whole experiment, but here the Ulvales did not become dominant, and Diplosoma sp. 1 only appeared in Week 10. In the case of Styrofoam, Ulvales and Obelia sp. 1 appeared in Week 4 and Diplosoma sp. 1 in Week 8 (Fig. 7).

Multivariate analyses (ANOSIM) showed significant differences in the structure of the communities among the 3 substrata throughout the entire experiment $(p<0.05)$. No consistent block effects were observed: only in Week 6, significant differences were

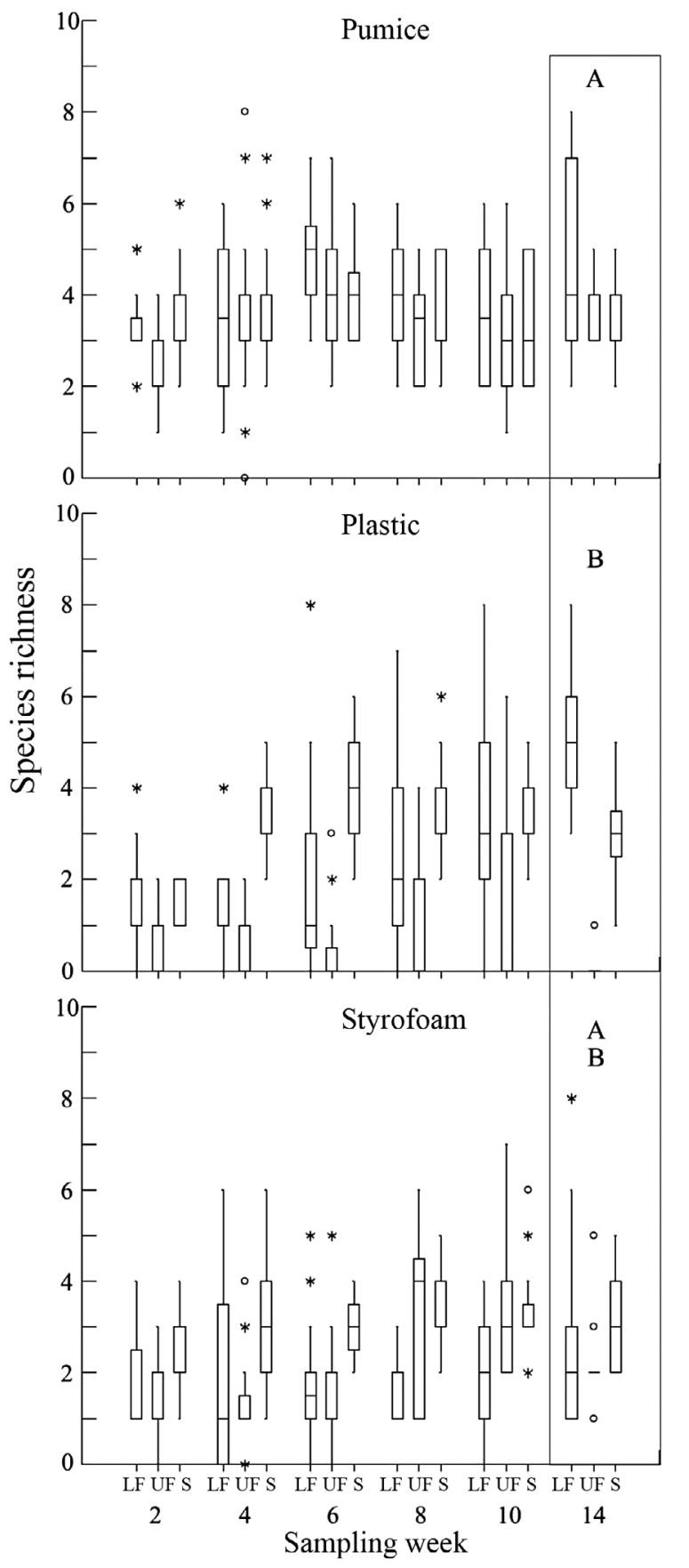

Fig. 6. Species richness on pumice, plastic, and Styrofoam plates on the lines during the different sampling dates. For each substratum the following 3 faces are shown: LF: lower face; UF: upper face; and S: side. Significant differences between the 3 substrata in Week 14 are shown with different capital letters. See Fig. 4 for further explanations

observed among some of the lines $(p=0.009)$, but these differences quickly disappeared thereafter (Table S3 in the supplement).

Floating stability (Cages). The effect of substratum on taxonomic richness after 14 wk significantly 


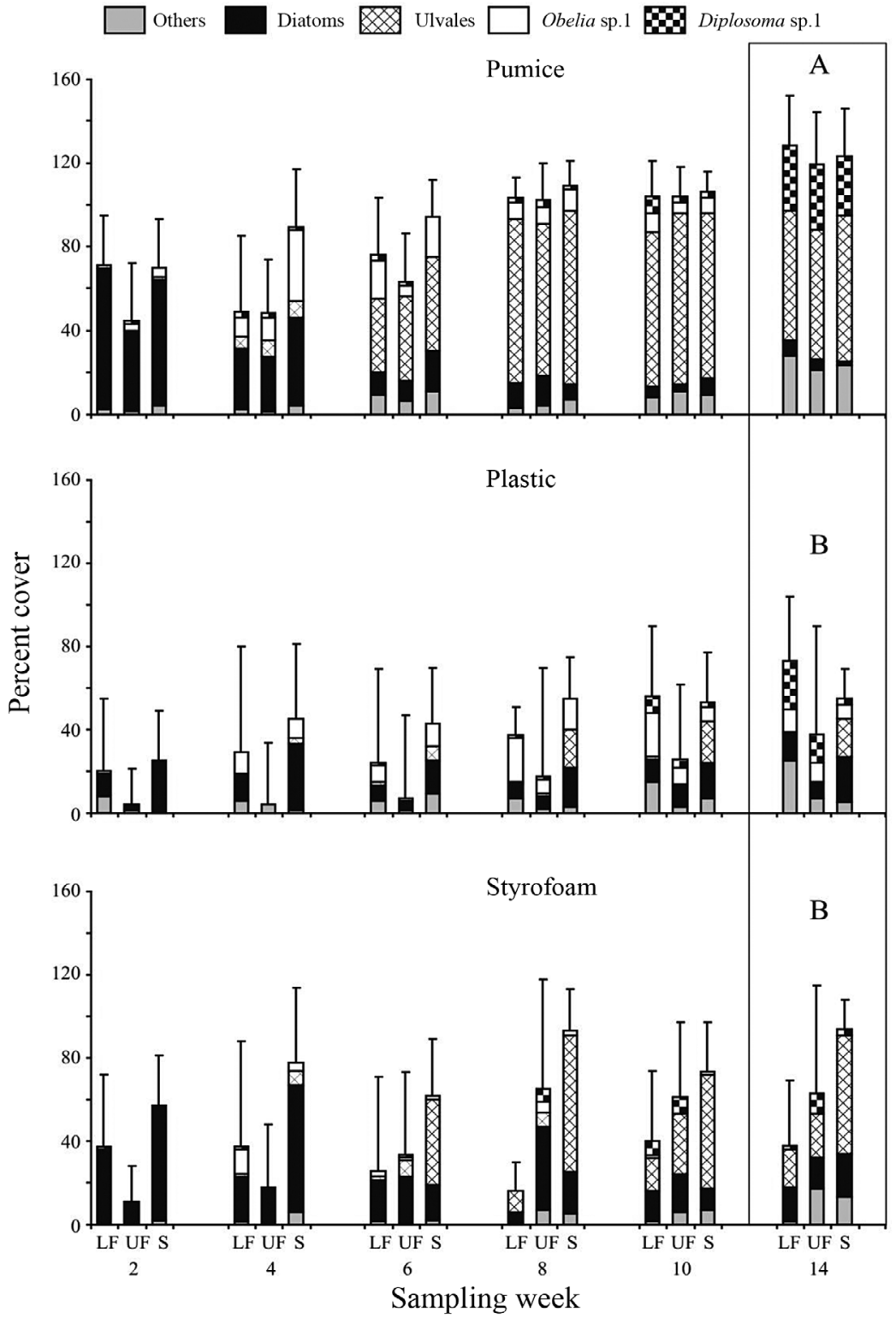

Fig. 7. Total \% cover and community composition on pumice, plastic, and Styrofoam plates on the lines during the different sampling dates. See Fig. 6 for further explanations

depended on face (face $\times$ substratum, $p<0.001$, Table S1 in the supplement). This interaction was consistent across blocks (face $\times$ block $\times$ substratum, $p=0.338$ ). The highest taxonomic richness was found in assemblages developing on the lower faces of plastic substrata (Fig. 8, Tukey's HSD p < 0.001). Within pumice substrata, species richness remained statistically similar across faces (Fig. 8, Tukey's HSD, $\mathrm{p}>0.05$ ); within plastic substrata, richness was highest on lower faces, followed by sides and upper faces; for Styrofoam, species richness was higher on the sides than on lower and upper faces (Fig. 8, Tukey's HSD, $\mathrm{p}<0.05)$.
At the end of the experiment (Week 14), cover significantly varied across substratum and face (face $\times$ substratum, $\mathrm{p}<0.001$, Table S1 in the supplement), and block had no effect on these differences (face $\times$ block $\times$ substratum, $\mathrm{p}=$ 0.959). In general, considering the 3 substrata, the highest \% cover was observed on the lower face of plastic substrata (Fig. 9, Tukey's HSD, p < 0.001). Within pumice pieces, assemblages developing on lower and upper faces showed the highest cover; within plastic pieces, lower faces showed the most abundant assemblages; within Styrofoam pieces, assemblages developing on the side showed the highest cover (Fig. 9, Tukey's HSD, p < 0.001).

In the first $2 \mathrm{wk}$, diatoms dominated on the 3 substrata, and in Week 4 Obelia sp. 1 appeared on the pumice and plastics. Both taxa persisted on these substrata until the end of the experiment. In the case of the pumice, Ulvales became abundant and maintained a high \% cover until the end of the experiment. On the plastics, the community was composed mainly of Obelia sp. 1, Ulvales, Tubularia sp. 1, and clonal ascidians from the genus Diplosoma, but none of these taxa showed a clear dominance. On Styrofoam, Ulvales also appeared, but only reached a low \% cover. In general, the community on the Styrofoam remained in an early successional stadium throughout the experiment with a clear predominance of diatoms (Fig. 9).

The ANOSIM showed significant differences among the structure of the communities of the 3 substrata from Week 4 until the end of the experiment $(p<0.05)$. Cage (= block) effects were found in Weeks 4,6 , and 14 $(p<0.05)$, but differences between individual cages shifted in a random pattern between subsequent samplings (Table $\mathrm{S} 4$ in the supplement).

\section{DISCUSSION}

\section{Substratum properties}

Herein we confirmed the high floating duration of abiotic substrata, exceeding $1 \mathrm{yr}$ of flotation for all 3 


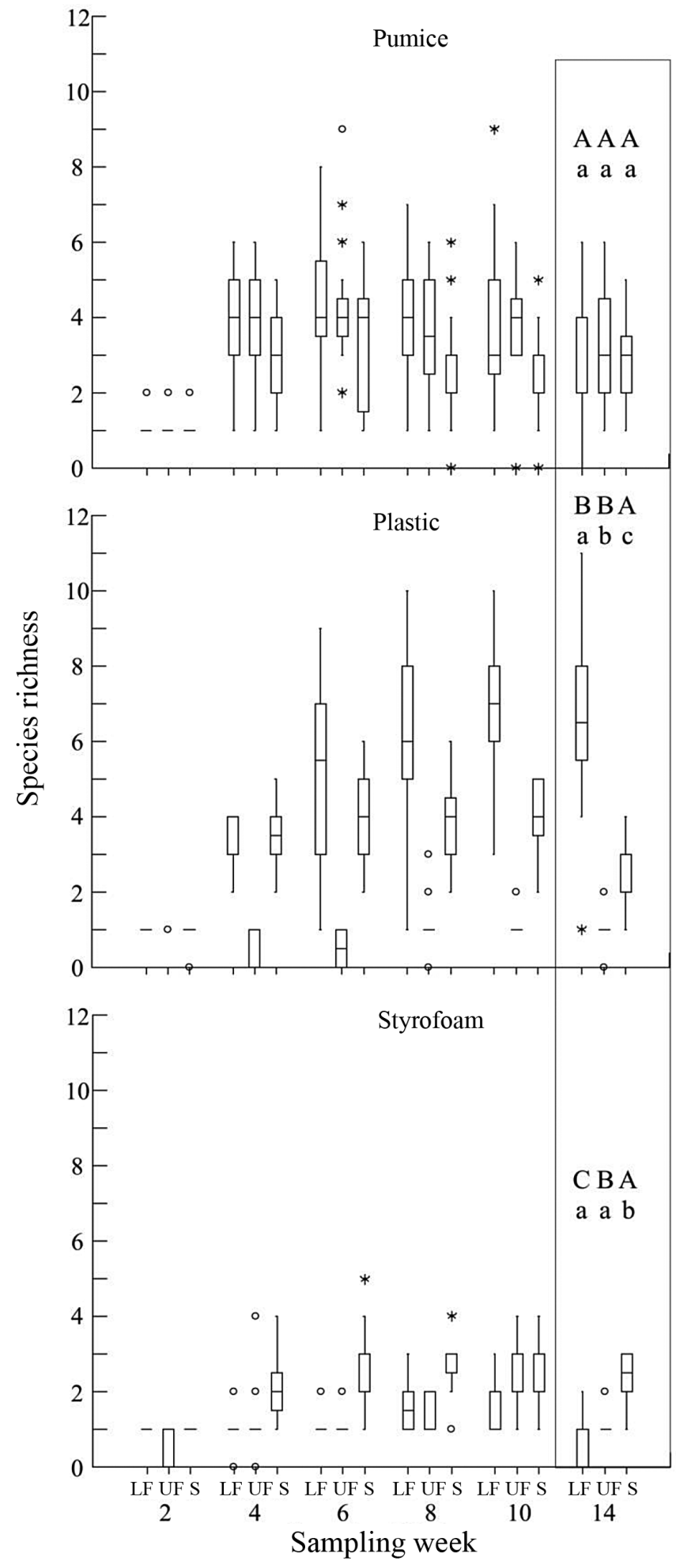

Fig. 8. Species richness on pumice, plastic, and Styrofoam pieces in the cages during the different sampling dates. Significant differences between the faces within each substratum in Week 14 are shown with different lowercase letters (comparisons between faces of each substratum need to be viewed in a horizontal direction). See Figs. $4 \& 6$ for further explanations substrata. Volcanic pumice had a shorter flotation time compared to the 2 anthropogenic substrata. This might be due to the erosion of interconnected gas vesicles in the pumice matrix causing the subsequent intrusion of water (Whitham \& Sparks 1986). Plastics and Styrofoam are anthropogenic objects of comparatively low density (Cundell 1974, Dixon \& Dixon 1981, Ye \& Andrady 1991) and appear to be substantially more resistant to degradation (Pegram \& Andrady 1989, Andrady et al. 1993). Accordingly, these substrata have a very long floating time in water (Gregory \& Andrady 2003).

During the formation of volcanic pumice, gas vesicles and crystals are incorporated into the matrix, which makes pumice a very porous and heterogeneous material (Richards 1958, Frick \& Kent 1984, Risso et al. 2002) with a very high surface rugosity (Whitham \& Sparks 1986). In the case of the anthropogenic materials such as plastics and Styrofoam, their surface rugosity can be highly variable, depending on the production processes and purposes of these materials (polystyrene, polyethylene, polypropylene, among others; Cundell 1974). Some of the most common plastic items with smooth surfaces are boxes, bags, and bottles, while plastic meshes, ropes, and Styrofoam are characterized by less homogeneous surfaces.

Even though some volcanic pumice have initial specific densities as low as 0.6 , the relatively rapid entry of water into some incompletely closed pores quickly leads to an increase of density (Whitham \& Sparks 1986), and consequently a high percentage of its surface area is below the sea surface (Jokiel 1989, 1990). The low density of plastics and Styrofoam (e.g. Ye \& Andrady 1991, Morét-Ferguson et al. 2010) and their capacity to retain volumes of air in hermetically closed spaces provide particularly high buoyancy to some of these substrata. A reduction in buoyancy can also be caused by organisms growing on floating substrata, as previously recorded for floating plastics (Ye \& Andrady 1991, Winston et al. 1997, Lobelle \& Cunliffe 2011). This effect, also suggested for pumice (Jokiel 1990, Bryan et al. 2004), was confirmed herein for the pumice pieces on the lines, where 3 replicates sank due to high epibiont biomass.

The floating stability of a substratum can have important consequences in the context of rafting. Herein it was found that Styrofoam is substantially less stable than pumice and plastics. These differences are probably caused by the different buoyancy and location of the centre of gravity of the 3 floating items. The Styrofoam pieces - due to their high buoyancy ( $>80 \%$ of their surface above the water) and 

Diatoms Ulvales Obelia sp.1 Tubularia sp.1

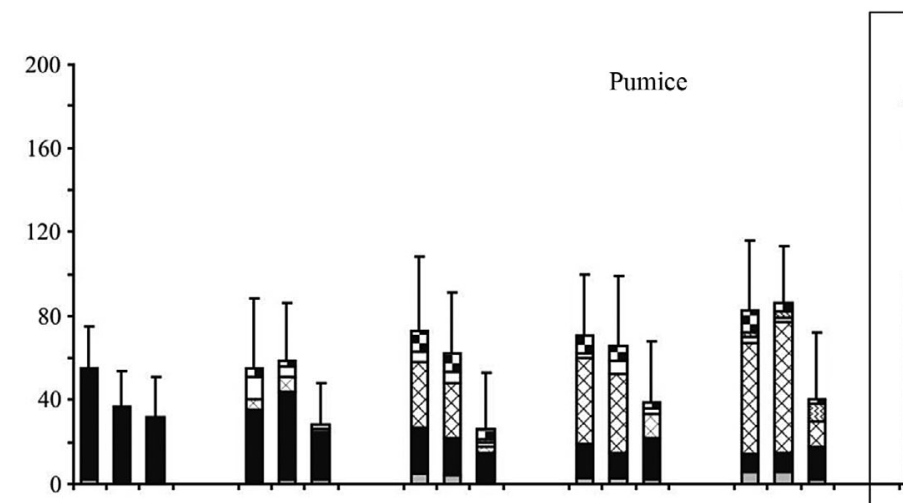

व.

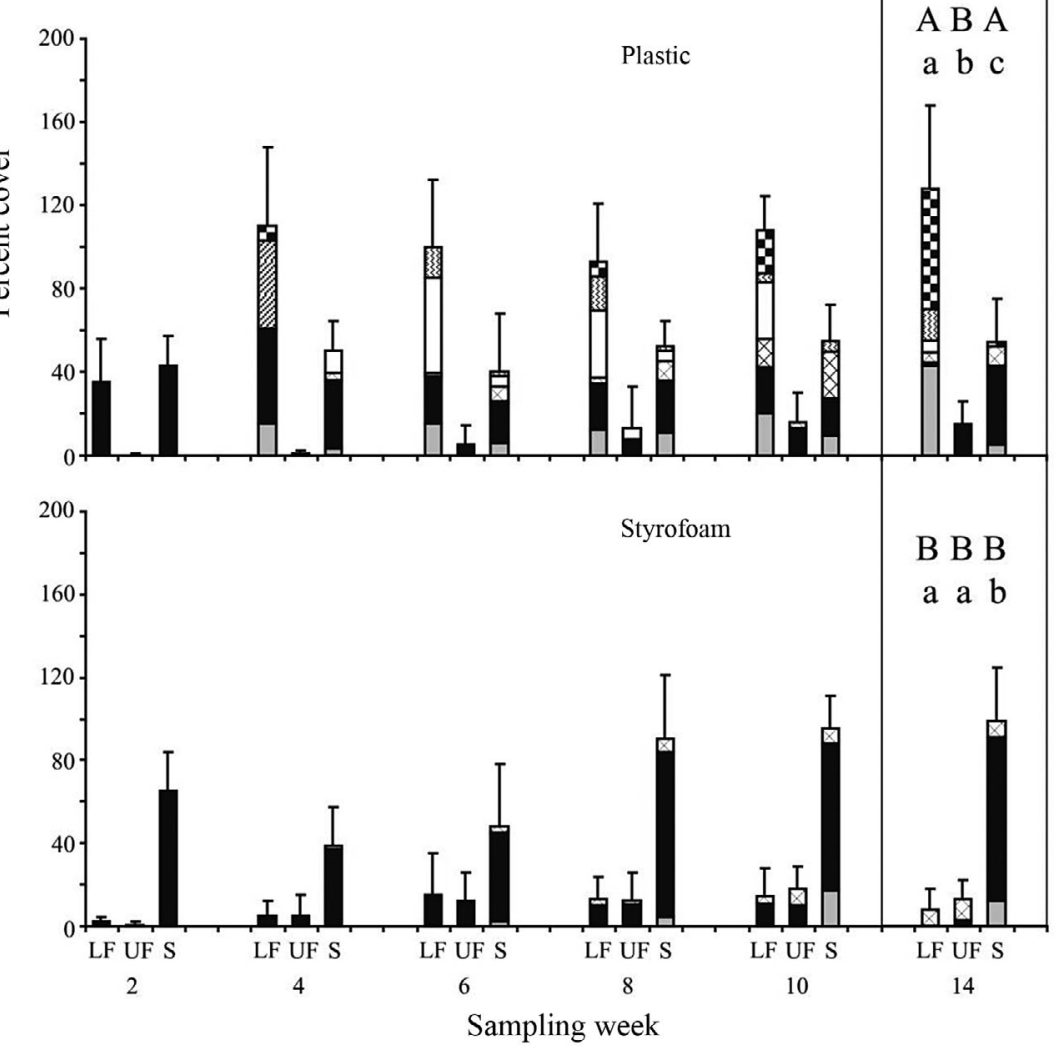

Fig. 9. Total \% cover and community composition on pumice, plastic, and Styrofoam plates in the cages during the different sampling dates. Significant differences between the faces within each substratum in Week 14 are shown with different lowercase letters (comparisons between faces of each substratum need to be viewed in horizontal direction). See Figs. $4 \& 6$ for further explanations

regular shapes - have their centre of gravity above the sea surface and close to the core of the object, resulting in repeated changes in position. In the case of the plastics used in our experiments, the centre of gravity is displaced toward one of the faces due to higher density of the outer lid. Consequently, the plastic jars usually floated with this lid-face below the sea surface. The pumice pieces mostly remained in one position, which partly can be explained by Diplosoma sp.1

their relatively low buoyancy. However, they turned occasionally over to a second position. This pattern of a primary and a secondary stable position is probably caused by their irregular shape and the fact that their centre of gravity is somewhat displaced from the core of the pumice piece. This property of floating objects (floating stability) has previously been suggested as a factor that might affect the fouling community growing on them (Thiel \& Gutow 2005b), but surprisingly, the importance of this factor has not yet been studied in a rigorous manner

\section{Colonization and surface properties of abiotic floating substrata}

Surface properties (in the Rings experiment) slightly affected the community succession of the 3 substrata, mainly because the succession on plastics differed from that on the other substrata. As predicted, plastics showed the lowest total \% cover at the beginning of the experiment, but then it increased continuously until the end of the experiment, when plastics surprisingly reached a higher coverage than both pumice and Styrofoam. Possibly, the low surface rugosity of plastics can explain these differences. Initially, the smooth surface of the plastic jars may have impeded successful settlement of some organisms. It has been suggested that in absence of a biofilm, surface rugosity determines the initial establishment of some species (Faimali et al. 2004). However, over time this effect would diminish (Bers \& Wahl 2004, Scardino \& de Nys 2004, Totti et al. 2007), because the developing biofilm attenuates the micro-topography of the substratum (Bers \& Wahl 2004). This diminishing effect could explain our results where differences among substrata disappeared between Weeks 4 and 10 . The significantly higher coverage on the plastics during the last sampling (Week 14) was marked by the increasing dominance of Austromegabalanus psittacus. This predominance on plastics can be explained 
by the better adhesion forces on smooth surfaces (see e.g. Berntsson et al. 2000, Herbert \& Hawkins 2006), reducing post settlement mortality of barnacles on plastics.

The taxonomic composition showed only minor differences among the 3 substrata. The taxa that appeared on the rings are common fouling species (Uribe et al. 2001, Callow \& Callow 2002), known to colonize a wide variety of surfaces such as cement, wood, plastics, and others (Dubois 1979, Viviani \& DiSalvo 1980, Uribe et al. 2001, Valdivia et al. 2005). We thus conclude that potentially all species found herein can settle on the 3 substrata, but that initial settlement of some species may be facilitated by the co-developing biofilm, while late-stage persistence may be enhanced by substratum properties such as surface smoothness and hardness. Survival of barnacles (herein Austromegabalanus psittacus) seems to be mostly affected by these different surface properties (e.g. Savoya \& Schwindt 2010), but some barnacles persisted on all 3 substratum types until the end of the experiment.

The intense and rapid colonization observed on all 3 substrata in the Rings experiment suggests that chemical composition of the substrata played either no, or only a minor role in the colonization. Styrofoam and other plastics such as polyethylene can become brittle over time (Cundell 1974, Andrady et al. 1993, Gregory \& Andrady 2003), but this did not seem to be of relevance for colonization in our experiments. In seawater, abiotic degradation (making substrata brittle) occurs over time scales (mo or even yr) that exceed the duration of our present experiments ( 100 d) (Pegram \& Andrady 1989, Andrady et al. 1993).

\section{Colonization and buoyancy of substrata}

Volcanic pumice had the highest taxonomic richness and highest coverage in the Lines experiment, which probably was caused by its low buoyancy. A large proportion of the pumice pieces were continuously under water, keeping their surface humid. This may have facilitated survival of recent settlers, explaining the higher taxonomic richness on pumice. Desiccation and solar radiation, which are known to negatively affect colonization of littoral benthic communities (Smith et al. 1986, Molis et al. 2003, Hung et al. 2005), may have suppressed taxonomic richness on the other 2 substrata. Both the plastic jars and the Styrofoam have a high buoyancy and always a large proportion of their surface above the water. Despite the differences between the substrata, all faces within a substratum type showed similar taxonomic richness or species cover, which suggests that buoyancy effects influenced the differences in colonization and succession on these substrata.

\section{Colonization and floating stability of substrata}

In the Cages experiment, where the substrata could float and overturn relatively freely, the highest $\%$ cover was observed on the volcanic pumice, where the community was mainly composed of Ulvales as of Week 6 . Green algae are common colonizers on floating substrata (Ye \& Andrady 1991). In previous studies on pumice rafting, it was observed that some algal species settle and grow preferentially in protected areas such as in porosities or cracks (Bryan et al. 2004). This can explain the dominance of Ulvales on pumice compared to plastics and Styrofoam. Contrary to the pumice, the Styrofoam was the substratum with the lowest \% cover and species richness throughout the experiment, which suggests that the multiple positional changes negatively affect the colonization on Styrofoam. Both the lower and upper faces of Styrofoam were frequently exposed to air, probably causing high mortality among some colonizers, as observed in other studies (Valentine et al. 2007) and herein on the lines (see 'Discussioncolonization and buoyancy of substrata').

Colonizers themselves may offer floating stability to a substratum, namely when some colonizers dominate on one face of the object, forming a sort of keel (e.g. Bryan et al. 2004). However, this does not seem to occur on Styrofoam, where the community persisted in the same initial successional stage throughout the experiment, most likely because the Styrofoam frequently turned over.

Colonization in the 2 experiments where substrata floated at the sea surface (Lines and Cages) presented differences mostly when analyzing the lateral areas of each substratum. During the $14 \mathrm{wk}$ in the cages, the pumice presented the lowest \% cover and taxonomic richness on the lateral area of the substratum. This was not observed on the lines where the lateral area occasionally even had a higher \% cover and taxonomic richness than either of the 2 faces. These differences among the experiments can be explained by erosion when touching each other (Frick \& Kent 1984, Bryan et al. 2004), which could impede establishment or survival of settlers (Jokiel 1989). It is considered that this kind of erosion also happens in nature, when large quantities of pumice are concentrated in oceanographic fronts (e.g. Richards 1958). 
In the case of the plastics in the cages, it was the face with the lid that presented the highest cover and taxonomic richness. The high floating stability of the plastics used in the present study might have favoured colonization. Since the face with the lid was continuously submerged, those taxa that are sensitive to ultraviolet radiation and desiccation probably experienced higher survival on this side (see also 'Discussion-colonization and buoyancy of substrata').

\section{Implications for rafting dispersal and outlook}

Even though in the present study pumice harboured a large number of taxa, its potential as a dispersal agent depends on its survival at the sea surface (Whitham \& Sparks 1986) and the impact of erosion (Frick \& Kent 1984). Pumice has a low frequency of occurrence in the world's oceans, which also reduces the likelihood of successful transport on this substratum. However, when pumice occurs, it can be very abundant (Richards 1958, Sutherland 1965, Coombs \& Landis 1966, Bryan et al. 2004), which enhances the probability of simultaneous arrival of potential colonizers. In the case of the plastics, it should be considered that the jars used in the present study had particular characteristics (internal and outer lid) that strongly influenced floating stability and colonization. Other plastics such as bottles (objects frequently floating in the sea; see e.g. Pruter 1987, Aliani \& Molcard 2003) may have a similarly low floating stability as Styrofoam. Consequently, the results from our experiment may not be representative for all plastic items at sea. However, even though not all plastics are good rafting substrata for associated organisms, their high frequency of occurrence makes them a topic of ecological concern because they may serve as dispersal vehicles for species from many different phyla (Stevens et al. 1996, Winston et al. 1997, Barnes 2002, Barnes \& Milner 2005, Gregory 2009). Styrofoam can float for long time periods, but colonization on this substratum was suppressed due to its low floating stability and high buoyancy. Consequently, Styrofoam can probably serve as dispersal agent only for a very limited number of organisms that grow during initial stages of community succession. Furthermore, Styrofoam is also exposed to frequent attacks by birds that confuse it with their prey (Laist 1987, Moser \& Lee 1992).

Most species found herein are facultative rafters (an exception being stalked barnacles from the genus Lepas), i.e. species from coastal environments that opportunistically colonize floating substrata. Thus, the studied substrata can be important dispersal vehicles for common coastal organisms, including invasive species such as Bugula neritina or Ciona intestinalis. In general, similar taxa colonize and might be transported on the 3 floating substrata, including soft-bodied organisms (21 of the 31 taxa found after $14 \mathrm{wk}$ were soft-bodied organisms). While there are no substantial differences in the species composition between the 3 substratum types, some species that did not occur on volcanic pumice, were recorded on plastics and Styrofoam. This is cause of concern, because the abundance and continuous presence of these anthropogenic substrata throughout the world's oceans might dramatically increase the probabilities of successful dispersal and colonization of organisms via rafting on abiotic substrata.

Acknowledgements. We thank L. Miranda and other members of the BEDIM (Biologia, Ecologia y Diversidad de Invertebrados Marinos) laboratory for their help during the survey of the experiments. Constructive comments from 2 anonymous reviewers helped to improve the original manuscript. Financial support for this project was received through FONDECYT (Fondo Nacional de Ciencia y Tecnologia) 1060127.

\section{LITERATURE CITED}

Aliani S, Molcard A (2003) Hitch-hiking on floating marine debris: macrobenthic species in the western Mediterranean Sea. Hydrobiologia 503:59-67

Andrady AL, Pegram JE, Song Y (1993) Studies on enhanced degradable plastics. II. Weathering of enhanced photodegradable polyethylenes under marine and freshwater floating exposure. J Polym Environ 1:117-126

Barnes DKA (2002) Invasions by marine life on plastic debris. Nature 416:808-809

Barnes DKA, Milner P (2005) Drifting plastic and its consequences for sessile organism dispersal in the Atlantic Ocean. Mar Biol 146:815-825

Barnes DKA, Galgani F, Thompson RC, Barlaz M (2009) Accumulation and fragmentation of plastic debris in global environments. Phil Trans R Soc B 364:1985-1998

Benedetti-Cecchi L, Bertocci I, Vaselli S, Maggi E (2006) Temporal variance reverses the impact of high mean intensity of stress in climate change experiments. Ecology 87:2489-2499

Berntsson KM, Jonsson PR, Lejhall M, Gatenholm P (2000) Analysis of behavioural rejection of micro-textured surfaces and implications for recruitment by the barnacle Balanus improvisus. J Exp Mar Biol Ecol 251:59-83

Bers AV, Wahl M (2004) The influence of natural surface microtopographies on fouling. Biofouling 20:43-51

Bryan AS, Cook A, Evans JP, Colls PW and others (2004) Pumice rafting and faunal dispersion during 2001-2002 in the southwest Pacific: record of a dacitic submarine explosive eruption from Tonga. Earth Planet Sci Lett 227: 135-154 
Callow ME, Callow JA (2002) Marine biofouling: a sticky problem. Biologist 49:10-14

> Cifuentes M, Kamlah C, Thiel M, Lenz M, Wahl M (2007) Effects of temporal variability of disturbance on the succession in marine fouling communities in northerncentral Chile. J Exp Mar Biol Ecol 352:280-294

> Connell JH, Slatyer RO (1977) Mechanisms of succession in natural communities and their role in community stability and organization. Am Nat 111:1119-1144

Coombs DS, Landis CS (1966) Pumice from the South Sandwich eruption of March 1962, reaches New Zealand. Nature 209:289-290

Cundell AM (1974) Plastics in the marine environment. Environ Conserv 1:63-68

> Dixon TR, Dixon TJ (1981) Marine litter surveillance. Mar Pollut Bull 12:289-295

Dubois R (1979) Marine fouling organisms, season and depth of settlement in Bahía La Herradura, Chile. Unpublished progress report. Centro Investigaciones Submarinas, Universidad del Norte

> Dudley TL, D'Antonio CM (1991) The effects of substrate texture, grazing, and disturbance on macroalgal establishment in streams. Ecology 72:297-309

Faimali M, Garaventa F, Terlizzi A, Chiantore M, CattaneoVietti R (2004) The interplay of substrate nature and biofilm formation in regulating Balanus amphitrite Darwin, 1854 larval settlement. J Exp Mar Biol Ecol 306: 37-50

Frick C, Kent LE (1984) Drift pumice in the Indian and South Atlantic oceans. Trans Geol Soc S Afr 87:19-33

Granhag LM, Finlay JA, Jonsson PR, Callow JA, Callow ME (2004) Roughness-dependent removal of settled spores of the green alga Ulva (syn. Enteromorpha) exposed to hydrodynamic forces from a water jet. Biofouling 20: $117-122$

Gregory MR (2009) Environmental implications of plastic debris in marine settings-entanglement, ingestions, smothering, hangers-on, hitch-hiking and alien invasions. Phil Trans R Soc B 364:2013-2025

Gregory MR, Andrady AL (2003) Plastics in the marine environment. In: Andrady AL (ed) Plastics and the environment. John Wiley \& Sons, Hoboken, NJ, p 379-401

> Herbert RJH, Hawkins SJ (2006) Effect of rock type on the recruitment and early mortality of the barnacle Chthamalus montagui. J Exp Mar Biol Ecol 334:96-108

> Hung OS, Gosselin LA, Thiyagarajan V, Wu R, Quian PY (2005) Do effects of ultraviolet radiation on microbial films have indirect effects on larval attachment of the barnacle Balanus amphitrite? J Exp Mar Biol Ecol 323: $16-26$

> Hutchinson N, Nagarkar S, Aitchison JC, Williams GA (2006) Microspatial variation in marine biofilm abundance on intertidal rock surfaces. Aquat Microb Ecol 42: 187-197

Jokiel PL (1984) Long distance dispersal of reef corals by rafting. Coral Reefs 3:113-116

> Jokiel PL (1989) Rafting of reef corals and other organisms at Kwajalein Atoll. Mar Biol 101:483-493

> Jokiel PL (1990) Transport of reef corals into the Great Barrier Reef. Nature 347:665-667

> Laist DW (1987) Overview of the biological effects of lost and discarded plastic debris in the marine environment. Mar Pollut Bull 18:319-326

Lobelle D, Cunliffe M (2011) Early microbial biofilm formation on marine plastic debris. Mar Pollut Bull 62: $197-200$

Molis M, Lenz M, Wahl M (2003) Radiation effects along UV-B gradient on species composition and diversity of a shallow-water macrobenthic community in the western Baltic. Mar Ecol Prog Ser 263:113-125

Moraga J, Olivares J (1993) Variabilidad térmica de la Bahía La Herradura de Guayacán, Coquimbo, Chile. Estud Oceanol 12:29-36

Morét-Ferguson S, Law KL, Proskurowski G, Murphy EK, Peacock EE, Reddy CM (2010) The size, mass, and composition of plastic debris in the western north Atlantic Ocean. Mar Pollut Bull 60:1873-1878

> Moser ML, Lee DS (1992) A fourteen-year survey of plastic ingestion by western north Atlantic seabirds. Colon Waterbirds 15:83-94

Pegram JE, Andrady AL (1989) Outdoor weathering of selected polymeric materials under marine exposure conditions. Polym Degrad Stabil 26:333-345

Platt WJ, Connell JH (2003) Natural disturbances and directional replacement of species. Ecol Monogr 73:507-522

> Pruter AT (1987) Sources, quantities and distribution of persistent plastic in the marine environment. Mar Pollut Bull 18:305-310

Quinn GP, Keough MJ (2002) Experimental design and data analysis for biologists. Cambridge University Press, Cambridge

R Development Core Team (2011) R: a language and environment for statistical computing, 2.11.1 ed. R Foundation for Statistical Computing, Vienna

Richards A (1958) Transpacific distribution of floating pumice from Isla San Benedicto, Mexico. Deep-Sea Res 5:20-35

- Risso C, Scasso RA, Aparicio A (2002) Presence of large pumice blocks on Tierra del Fuego and South Shetland Islands shorelines, from 1962 South Sandwich Islands eruption. Mar Geol 186:413-422

Ryan PG, Moore CJ, van Franeker JA, Moloney CL (2009) Monitoring the abundance of plastic debris in the marine environment. Phil Trans R Soc B 364:1999-2012

Savoya V, Schwindt E (2010) Effect of the substratum in the recruitment and survival of the introduced barnacle Balanus glandula (Darwin 1854) in Patagonia, Argentina. J Exp Mar Biol Ecol 382:125-130

Scardino AJ, de Nys R (2004) Fouling deterrence on the bivalve shell Mytilus galloprovincialis: a physical phenomenon? Biofouling 20:249-257

Smith CM, Satoh K, Fork DC (1986) The effects of osmotic tissue dehydration and air drying on morphology and energy transfer in two species of Porphyra. Plant Physiol 80:843-847

Stevens LM, Gregory MR, Foster BA (1996) Fouling Bryozoa on pelagic and moored plastics from northern New Zealand. In: Gordon DP, Smith AM, Grant-Mackie JA (eds) Bryozoans in space and time. NIWA, Wellington, p 321-340

> Sutherland FL (1965) Dispersal of pumice, supposedly from the 1962 South Sandwich Island eruption, on southern Australian shores. Nature 207:1332-1335

Thiel M, Gutow L (2005a) The ecology of rafting in the marine environment. I. The floating substrata. Oceanogr Mar Biol Annu Rev 42:181-264

Thiel M, Gutow L (2005b) The ecology of rafting in the marine environment. II. The rafting organisms and community. Oceanogr Mar Biol Annu Rev 43:279-418 
Totti C, Cucchiari E, De Stefano M, Pennesi C, Romagnoli T, Bavestrello G (2007) Seasonal variations of epilithic diatoms on different hard substrates, in the northern Adriatic Sea. J Mar Biol Assoc UK 87:649-658

Tsikhon-Lukanina EA, Reznichenko OG, Nikolaeva GG (2001) Ecology of invertebrates on the oceanic floating substrata in the Northwest Pacific Ocean. Okeanologiya 41:525-530

Underwood AJ, Chapman MG (2006) Early development of subtidal macrofaunal assemblages: relationships to period and timing of colonization. J Exp Mar Biol Ecol 330:221-233

Uribe E, Lodeiros C, Felix-Pico E, Etchepare I (2001) Epibiontes en pectínidos de Iberoamerica. In: MaedaMartínez, AN (ed) Los Moluscos pectínidos de Iberoamerica: Ciencias y Acuicultura. Editorial Limusa, México, p 249-266

Valdivia N, Heidemann A, Thiel M, Molis M, Wahl M (2005) Effects of disturbance on the diversity of hard-bottom macrobenthic communities on the coast of Chile. Mar Ecol Prog Ser 299:45-54

Editorial responsibility: Brian Helmuth, Columbia, South Carolina, USA
Valentine PC, Carman MR, Blackwood DS, Heffron EJ (2007) Ecological observations on the colonial ascidian Didemnum sp. in a New England tide pool habitat. J Exp Mar Biol Ecol 342:109-121

Viviani CA, DiSalvo LH (1980) Biofouling in a north-central Chilean coastal bay. Proc 5th Int Congr on Marine Corrosion and Fouling, Barcelona, p 69-74

> Wahl M, Hoppe K (2002) Interactions between substratum rugosity, colonization density and periwinkle grazing efficiency. Mar Ecol Prog Ser 225:239-249

Whitham AG, Sparks RSJ (1986) Pumice. Bull Volcanol 48:209-223

Winston JE, Murray RG, Stevens LM (1997) Encrusters, epibionts, and other biota associated with pelagic plastics. A review of biogeographical, environmental, and conservation issues. In: Coe JM, Rogers DB (eds) Marine debris: sources, impacts, and solutions. Springer-Verlag, New York, p 81-97

Ye S, Andrady AL (1991) Fouling of floating plastic debris under Biscayne Bay exposure conditions. Mar Pollut Bull 22:608-613

Submitted: May 31, 2011; Accepted: August 15, 2011

Proofs received from author(s): September 28, 2011 